\title{
Nosocomial Transmission of Hepatitis C Virus Associated With The Use of Multidose Saline VIALS
}

Gérard Krause, MD, DrMed; Mary Jo Trepka, MD, MPH; Robert S. Whisenhunt; Dolly Katz, PhD; Omana Nainan, PhD; Steven T. Wiersma, MD, MPH; Richard S. Hopkins, MD, MSc

\begin{abstract}
OBJECTIVE: To identify the source of an outbreak of acute hepatitis $\mathrm{C}$ virus (HCV) infection among 3 patients occurring within 8 weeks of hospitalization in the same ward of a Florida hospital during November 1998

DESIGN: A retrospective cohort study was conducted among 41 patients hospitalized between November 11 and 19, 1998. Patients' blood was tested for antibodies to HCV, and HCV RNA-positive samples were genotyped and sequenced.

RESULTS: Of the 41 patients, $24(59 \%)$ participated in the study. HCV genotype $1 \mathrm{~b}$ infections were found in 5 patients. Three of 4 patients who received saline flushes from a multidose saline vial on November 16 had acute HCV infection, whereas

none of the 9 patients who did not receive saline flushes had HCV infection $(P=.01)$. No other significant exposures were identified. The HCV sequence was available for 1 case of acute $\mathrm{HCV}$ and differed by a single nucleotide $(0.3 \%)$ from that of the indeterminate case.

CONCLUSION: This outbreak of HCV probably occurred when a multidose saline vial was contaminated with blood from an HCV-infected patient. Hospitals should emphasize adherence to standard procedures to prevent blood-borne infections. In addition, the use of single-dose vials or prefilled saline syringes might further reduce the risk for nosocomial transmission of bloodborne pathogens (Infect Control Hosp Epidemiol 2003;24:122-127).
\end{abstract}

Several outbreaks of nosocomial transmission of hepatitis $\mathrm{C}$ virus (HCV) have been linked to breaches in standard precautions for blood-borne infections during nursing procedures ${ }^{1}$ or interventions such as colonoscopy, ${ }^{2}$ surgery, ${ }^{3}$ and dialysis. ${ }^{3}$ In other reports of $\mathrm{HCV}$ outbreaks, although the route of transmission could not be identified, failure to follow standard procedures was suspected in most instances. ${ }^{4-11}$ In reports on other types of outbreaks, saline flushes of indwelling peripheral intravenous cannulas have been linked to nosocomial transmission of pathogens other than $\mathrm{HCV}^{12-16}$

In August 1999, three patients diagnosed as having $\mathrm{HCV}$ infection within 8 weeks of being discharged from the same hospital in southern Florida were reported to the Florida Department of Health. All three patients had been hospitalized in the same ward of a 150-bed hospital between November 11 and 19, 1998. The results of previous tests for hepatitis A and B were negative. Hospital officials conducted an internal investigation, including testing of most hospital staff members for antibody to $\mathrm{HCV}$ (anti-HCV), but were unable to identify the source of the outbreak. All serum samples from staff members were negative for anti-HCV. Subsequently, the Florida Department of Health was asked to investigate the outbreak to identify its source. We conducted an epidemiologic investigation of patient-to-patient transmis-

sion of $\mathrm{HCV}$ that identified exposure to saline flushes as a risk factor for infection.

\section{METHODS}

\section{Case Definitions and Case Ascertainment}

An acute case was defined as a patient hospitalized in the ward between November 11 and 19, 1998, with (1) a positive antibody test against HCV; (2) onset of jaundice after November 26, 1998; (3) serum aminotransferase levels greater than 1,000 IU/L; and (4) no evidence of prior HCV infection. A chronic case was defined as a patient hospitalized in the ward between November 11 and 19, 1998, with a diagnosis of $\mathrm{HCV}$ infection before admission. An indeterminate case was defined as a patient hospitalized in the ward between November 11 and 19, 1998, with (1) a positive antibody test against $\mathrm{HCV}$ and (2) no evidence of jaundice, elevated serum aminotransferase levels, or prior $\mathrm{HCV}$ infection.

Patients hospitalized in the ward between November 11 and 19, 1998, were contacted either directly or through their primary physicians. Patients were informed of the possible nosocomial transmission of hepatitis $\mathrm{C}$ and were offered a test for $\mathrm{HCV}$ infection. Serum samples of patients were tested first by enzyme immunoassay (EIA) (HCV-EIA version 3.0, Ortho-Clinical Diagnostics, Rochester, NY).

Dr. Krause is from the Epidemic Intelligence Service, State Branch, Epidemiology Program Office, Centers for Disease Control and Prevention, Atlanta, Georgia. Drs. Krause, Katz, Wiersma, and Hopkins are from the Bureau of Epidemiology, Florida Department of Health, Tallahassee, Florida. Dr. Trepka and Mr. Whisenhunt are from the Miami-Dade County Health Department, Miami, Florida. Dr. Nainan is from the Hepatitis Branch, Division of Viral and Rickettsial Diseases, National Center for Infectious Diseases, Centers for Disease Control and Prevention, Atlanta, Georgia.

Address reprint requests to Gérard Krause, Infektionsepidemiologie, Robert Koch-Institut, Seestr. 10, 13353 Berlin, Germany.

The authors thank the staff of the hospital and the patients for cooperating in the investigation as well as the following staff at the Miami-Dade County Health Department: Letty Bassart, Miguel Cruz, Marc Diamante, and Jorge Hermida. The authors also thank Dr. Beth Bell, Dr. William Jarvis, Dr. Andrew Pelletier, and Dr. Ian Williams for their support. 
Samples that were repeatedly reactive by EIA were subsequently confirmed by RIBA HCV 3.0 Strip Immunoblot Assay (Chiron Corp., Emeryville, CA).

\section{Review of Medical Records and Patient Interviews}

The medical records of all patients hospitalized in the ward between November 11 and 19, 1998, were reviewed. Data on medical history, diagnosis, diagnostic procedures, surgical interventions, medications, and other treatments were collected. Any medication or diagnostic procedure that involved access to the patient's vascular system was recorded with the day and time of exposure. These exposures included intravenous medication, infusions, transfusions, phlebotomy, and capillary blood sugar tests.

Patients who tested positive for anti-HCV were interviewed regarding symptoms, medical history, and risk factors for hepatitis C. Risk factors were defined as any of the following: injection drug use, history of sexually transmitted diseases, hemodialysis, blood transfusions or blood components before 1992, organ transplants before 1992, or receipt of clotting factor concentrates produced before $1987 .{ }^{17}$

\section{Retrospective Cohort Study}

A retrospective cohort study was conducted among patients who were tested for anti-HCV, using the case classification as the outcome variable. Indeterminate and chronic cases were excluded from the analysis because their status as a source or recipient of infection could not be determined with certainty. Exposures shared by acute case patients were analyzed by day and time of exposure. Six time periods per day of 1 to 6 hours each were defined to compare exposures. Longer time periods were chosen for hours during which few medical or nursing interventions occurred, and shorter time periods were chosen for times of frequent exposures. $P$ values (Fisher's exact test) were calculated using Epi-Info software (version 6.0; Centers for Disease Control and Prevention, Atlanta, GA).

\section{Genotyping and Sequencing of $\mathrm{HCV}$}

Anti-HCV-positive specimens were tested for $\mathrm{HCV}$ RNA by nested reverse transcription polymerase chain reaction (RT PCR) amplification of the 5' noncoding region. ${ }^{18,19}$ PCR products were separated by electrophoresis on a $2 \%$ agarose (GIBCO-BRL, Carlsbad, CA) and by positive specimens identified with ethidium bromide staining.

HCV genotypes were determined for HCV RNA-positive specimens from the 300-nucleotide-long sequence of the nonstructural coding region $5 \mathrm{~b}$ (NS5b). ${ }^{19-21} \mathrm{PCR}$ products were purified and sequenced using an automated DNA sequencer (ABI 377, Applied Biosystems Inc., Foster City, CA). Genotypes were defined using a multiple sequence alignment program (Pileup, Wisconsin Genetic Computer Group, Madison, WI). ${ }^{22}$

To determine the relatedness of $\mathrm{HCV}$ isolates, quasispecies of the hypervariable region 1 were determined by limiting dilution PCR for each HCV RNA-positive specimen as described below. Nested RT PCR was performed to determine the endpoint titer, using the following primers: first round 1350F1 (forward primer 5'-GCTACTCCGGATCCC ACAAGC-3') and 1633R (reverse primer 5'TCATTGCAGTTCAGGGCCGT-3'), and second round 1426F1 (forward primer 5'-TATTCCATGGTGGGGAACTGG -3 ') and 1619R (reverse primer 5'-GCAGTCCTGTTGATG TGCCA-3'). Multiple PCR reactions (30 to 40) were then performed at twice the serum dilution of the endpoint PCR titer. Each PCR amplicon was purified, and the nucleotide sequence determined as described previously.

Pairwise analysis of nucleotide sequences was performed using multiple sequence alignment programs (Pileup and Pretty, Wisconsin Genetic Computer Group). Distribution of nucleotide distances was calculated using Jukes-Cantor distance correction (Evolutionary Distance, Wisconsin Genetic Computer Group).

\section{Site Inspection and Review of Procedures}

The ward was visited on August 25 and 26, 1999, and the materials used to administer medications were inspected. Staff assignment sheets were reviewed to determine which patients shared the same nurses during each shift. Staff members were asked to demonstrate procedures that involved phlebotomy, intravenous medication, or any other access to the vascular system of patients, such as blood sugar testing.

\section{RESULTS}

\section{Case Ascertainment}

Between November 11 and 19, 1998, a total of 41 patients were hospitalized on the ward. By the time the investigation was started in August 1999, 15 (37\%) of the patients had died; none of these patients had hepatitis or liver disease listed as a cause of death on the death certificate. Two (5\%) of the patients could not be located. Thus, $24(59 \%)$ of the patients were available to provide blood samples for testing. Five (21\%) of the 24 samples were positive for anti-HCV.

\section{Review of Medical Records and Patient Interviews}

Twenty-one women and 20 men comprised the 41 patients hospitalized in the ward between November 11 and 19, 1998. Patients' ages ranged from 18 to 93 years, with a median of 77 years. The mean age of the 24 patients (12 women and 12 men) who were tested for anti-HCV was 72 years versus a mean age of 83 years for the 17 patients (9 women and 8 men) who were not tested. The mean length of hospitalization was 10 days. Admission diagnoses included a variety of cardiac, gastrointestinal, traumatic, and gynecologic problems. Most admissions resulted from geriatric health problems. Thirty-nine (95\%) of the patients had an indwelling peripheral intravenous cannula, 10 (24\%) of the patients underwent surgery, 6 (14\%) of the patients underwent gastroenterologic interventions, 5 (12\%) of the patients underwent radiologic imaging with contrast medium, $3(7 \%)$ of the patients had a central venous catheter, 
TABLE 1

Characteristics of Patients With Hepatitis C Virus Infection as of August 1999 Who Were Hospitalized in the Same Ward BETWEeN NOVEMBER 11 AND 19, 1998

\begin{tabular}{|c|c|c|c|c|c|c|c|c|}
\hline Patient & $\begin{array}{r}\text { Age } \\
\text { (y) }\end{array}$ & Gender & $\begin{array}{c}\text { Anti-HCV Test } \\
\text { Before Admission }\end{array}$ & $\begin{array}{l}\text { Onset of } \\
\text { Jaundice }\end{array}$ & $\begin{array}{l}\text { Admission } \\
\text { Diagnosis }\end{array}$ & $\begin{array}{c}\text { Dates of } \\
\text { Stay in Ward }\end{array}$ & $\begin{array}{c}\text { Risk } \\
\text { Factors? }\end{array}$ & $\begin{array}{c}\text { Case } \\
\text { Classification } \\
\end{array}$ \\
\hline A & 34 & M & Negative 11/95 & $1 / 17 / 99$ & Asthma & $11 / 11 / 98-11 / 17 / 98$ & No & Acute \\
\hline B & 18 & $\mathrm{~F}$ & Not done & $12 / 5 / 98$ & $\begin{array}{l}\text { Guillain-Barré } \\
\text { syndrome }\end{array}$ & $11 / 12 / 98-11 / 19 / 98$ & No & Acute \\
\hline $\mathrm{C}$ & 51 & $\mathrm{~F}$ & Not done & $1 / 7 / 99$ & Asthma & $11 / 12 / 98-11 / 19 / 98$ & No & Acute \\
\hline $\mathrm{D}$ & 82 & M & Not done & None & $\begin{array}{l}\text { Chronic obstructive } \\
\text { pulmonary disease }\end{array}$ & $11 / 13 / 98-11 / 18 / 98$ & Unknown & Indeterminate \\
\hline $\mathrm{E}$ & 66 & $\mathrm{~F}$ & Positive 1990 & 1990 & Pancreatitis & $11 / 13 / 98-12 / 13 / 98$ & Yes & Chronic \\
\hline
\end{tabular}

and $6(15 \%)$ of the patients underwent other invasive interventions.

According to the medical history and laboratory results, 3 patients had acute cases (patients $\mathrm{A}, \mathrm{B}$, and C), 1 patient had an indeterminate case (patient $\mathrm{D}$ ), and 1 patient had a chronic case (patient E) of hepatitis C (Table 1). All 5 case-patients received intravenous medications through indwelling peripheral intravenous cannulas, but they did not have the same medications in common. None of the case-patients underwent surgery, gastroscopy, dialysis, or a blood transfusion during their hospitalization in the ward. The exposures shared by all 3 acute case-patients (patients $\mathrm{A}, \mathrm{B}$, and $\mathrm{C}$ ) were having an indwelling peripheral intravenous cannula, receiving any kind of intravenous medication, receiving saline flushes of the indwelling peripheral intravenous cannula, and undergoing venous phlebotomy. Patients A and B had intramuscular medication, and patients $A$ and $C$ received nebulizer treatments. Patient $B$ underwent a spinal tap, and patient $\mathrm{C}$ underwent subcutaneous insulin and capillary blood tests.

The onset of signs and symptoms of acute hepatitis C occurred in patients A, B, and C during December 1998 and January 1999; none of these patients had identified risk factors for HCV infection. Patient D died in November 1999 without developing signs or symptoms of hepatitis. This patient had received multiple blood transfusions from 1997 to 1999 but not during his hospitalization in the ward in November 1998. Although this patient could not be interviewed, his relatives and primary care physicians reported no knowledge of any risk factors for $\mathrm{HCV}$ infection. Patient E had been diagnosed as having HCV infection in 1990; she had received multiple blood transfusions in 1975 in Cuba and reported no other risk factors for $\mathrm{HCV}$ infection.

\section{Retrospective Cohort Study}

Twenty-four patients were included in the cohort study; 3 of these patients had acute hepatitis C (patients A, B, and $\mathrm{C}$ ) and were considered acute cases. The remaining 19 patients tested negative for anti-HCV. Patients D and E were excluded from the analysis. Exposure to indwelling peripher- al intravenous cannulas was tested for the entire period of hospitalization because the dates on the installation or exchange of the cannulas were not available. The only exposure that yielded a trend for an association with acute $\mathrm{HCV}$ infection was saline flush of indwelling peripheral intravenous cannulas. During six time periods of 1 to 6 hours each, all 3 acute case-patients received a saline flush. During those times, the only exposure significantly associated with acute $\mathrm{HCV}$ infection was the saline flush on November 16 at 10:00 $\mathrm{pm}$ (Table 2). This was one of four times during which patient $\mathrm{D}$, the indeterminate case-patient, received a saline flush before the 3 acute case-patients.

\section{Genotyping and Sequencing of $\mathrm{HCV}$}

The genotype of all five samples was $1 \mathrm{~b}$. Samples from patients $\mathrm{B}, \mathrm{D}$, and $\mathrm{E}$ were PCR positive and were sequenced. Two samples could not be sequenced (patients $\mathrm{A}$ and $\mathrm{C}$ ) because viral material was no longer available. In a pairwise analysis, the sequences of the NS5b region of the $\mathrm{HCV}$ from patients $\mathrm{B}$ and $\mathrm{D}$ differed by a single nucleotide $(0.3 \%)$, and the $\mathrm{HCV}$ from patient $\mathrm{E}$ differed from the virus from patients B and D by 9 nucleotides (3\%).

Relatedness of $\mathrm{HCV}$ isolates was evaluated by hypervariable region 1 quasi-species analysis. A single hypervariable region 1 quasi-species with identical sequence was obtained from the HCV from patient B by limiting dilution PCR ( $\mathrm{n}=20$ amplicons). Multiple quasi-species variants were isolated from patient $\mathrm{D}(\mathrm{n}=16$ amplicons) and patient $\mathrm{E}$ ( $\mathrm{n}=19$ amplicons) with sequence variation between each other ranging from $0 \%$ to $2 \%$. The hypervariable region 1 quasi-species sequences of the $\mathrm{HCV}$ from patients $\mathrm{B}$ and $\mathrm{D}$ varied by a single nucleotide. The nucleotide identity was $99 \%$ between the sequences of the $\mathrm{HCV}$ from patients B and D. The hypervariable region 1 sequences obtained by limiting dilution PCR from the HCV from patient $\mathrm{E}$ had only $72 \%$ identity with the HCV from patients B and D.

\section{Site Inspection and Review of Procedures}

The ward had three rooms with two beds and 12 single-bed rooms, and was divided into two sections with nine 
TABLE 2

Exposures* Among Patients With Hepatitis C Virus Infection Hospitalized in the Same Ward Between November 11 and 19 , 1998

\begin{tabular}{|c|c|c|c|}
\hline Type and Time of Exposure & $\begin{array}{c}\text { Acute HCV Infections } \\
\text { Among Exposed }\end{array}$ & $\begin{array}{c}\text { Acute HCV Infections } \\
\text { Among Unexposed }\end{array}$ & P Value \\
\hline Intravenous injection, Nov. 11-19 & $3 / 12$ & $0 / 10$ & .14 \\
\hline Indwelling peripheral intravenous cannula, Nov. $11-19^{\dagger}$ & $3 / 19$ & $0 / 2$ & .73 \\
\hline Venous blood test, Nov. 11-19 & $3 / 20$ & $0 / 2$ & .74 \\
\hline Saline flush, Nov. 11-19 & $3 / 14$ & $0 / 8$ & .24 \\
\hline Nov. 14: 6:00-10:00 $\mathrm{pm}^{\ddagger}$ & $3 / 7$ & $0 / 2$ & .42 \\
\hline Nov. $14-15: 10: 00 \mathrm{pm}-1: 00 \mathrm{am}^{\S}$ & $3 / 7$ & $0 / 2$ & .42 \\
\hline Nov. 15: 12:00-6:00 $\mathrm{pm}^{\ddagger}$ & $3 / 6$ & $0 / 3$ & .24 \\
\hline Nov. 15: 10:00 $\mathrm{pm}^{\S}$ & $3 / 5$ & $0 / 4$ & .12 \\
\hline Nov. 16: 9:00 am-3:00 pm & $3 / 7$ & $0 / 6$ & .12 \\
\hline Nov. 16: 10:00 $\mathrm{pm}^{\ddagger}$ & $3 / 4$ & $0 / 9$ & .01 \\
\hline \multicolumn{4}{|c|}{$\begin{array}{l}\mathrm{HCV}=\text { hepatitis } \mathrm{C} \text { virus. } \\
{ }^{*} \text { Exposures shared by at least } 2 \text { cases. } \\
\text { } \text { Total is } 21 \text { patients instead of } 22 \text { patients as for other exposures because information was not available for } 1 \text { patient. } \\
\text { ₹Time periods } \leqslant 6 \text { hours during which all } 3 \text { acute case-patients received a saline flush within } 1 \text { hour after the indeterminate case-patient received a saline flush. } \\
\text { \$Time periods } \leqslant 6 \text { hours during which all } 3 \text { acute case-patients received a saline flush. } \\
\text { "Fisher's exact test. }\end{array}$} \\
\hline
\end{tabular}

patients in each section. There were two nursing teams; each team was primarily responsible for one of the two sections. Patients $\mathrm{C}$ and $\mathrm{E}$ shared one room, which was located across the hall from the room of patient $A$ in the first section. Patients B and D stayed in two adjacent single-bed rooms in the second section.

The hospital used a computerized system for drugs and nursing supplies that kept individual accounts of all items used for each patient. This system prevented the sharing of medications and nursing supplies. The only medication that was not individually stored and assigned for patient use was saline solution used to prepare flushes of indwelling peripheral intravenous cannulas. The saline solution was in 30-mL multidose vials that were stored on a medication cart and used by all nurses in both sections of the ward. Only one vial was opened at a time. Saline flushes were performed before and after each intravenous medication or by schedule, usually once per nursing shift.

Nurses were able to explain the standard precautions for the prevention of blood-borne infections and stated that they adhered to the precautions. According to interviews with the nurses, the saline flushes were prepared by inserting a single-use needle into the multidose vial and drawing approximately $3 \mathrm{~mL}$ into a single-use syringe. The needle was then discarded, and the syringe was connected directly to the indwelling peripheral intravenous cannulas, injecting the saline solution. On the basis of the nurse assignment sheets, the 3 acute case-patients did not share the same nurse during any shift.

\section{DISCUSSION}

The results of this epidemiologic investigation suggest that three patients were infected with $\mathrm{HCV}$ by injection of saline solution from a multidose vial that might have been contaminated with the blood of another patient. Five lines of evidence support this conclusion. First, the HCV infection of all five case-patients had genotype $1 \mathrm{~b}$, which has an estimated prevalence of $17 \%$ among HCV-infected individuals in the general U.S. population. ${ }^{19}$ Second, the sequencing results demonstrate a close genetic resemblance between the viruses of one acute case-patient (patient B) and the indeterminate case-patient (patient D), suggesting patient-to-patient transmission. Third, saline solution was the only substance for intravenous use in the ward that was kept in multidose vials to be used for more than one patient. Fourth, the epidemiologic analysis identified exposure to saline flushes as the only significant risk factor for acute $\mathrm{HCV}$ infection. Fifth, the indeterminate case-patient received a saline flush before the three acute case-patients on November 16 at 10:00 pm, which is consistent with the possibility of the saline solution being contaminated with the blood of the indeterminate case-patient.

Although all five patients with HCV infection had genotype $1 \mathrm{~b}$, the sequencing results indicated that patient E (the chronic case) was not connected to patients B (an acute case) and D (the indeterminate case). The larger variation of quasi-species for the virus from patient $\mathrm{D}$ would be consistent with the hypothesis that his infection was of longer duration than patient B's infection. ${ }^{23}$ If this outbreak resulted from a single incident, patient $\mathrm{D}$ was the most likely source for infection of patients $\mathrm{A}, \mathrm{B}$, and $\mathrm{C}$.

We could not determine exactly how the saline solution was contaminated with $\mathrm{HCV}$, especially because the nurses said they adhered to the standard precautions against transmission of blood-borne pathogens and denied filling the same syringe twice from a multidose vial. The medication records in the hospital did not always indicate the order in which patients received saline flushes during a given time. However, there were four times when the indeterminate case-patient received a saline flush before the 
three acute case-patients. A possible scenario is that the 3$\mathrm{mL}$ saline flush in the source patient was not sufficient to clear the indwelling peripheral intravenous cannula, and the nurse used the same syringe to draw an additional $3 \mathrm{~mL}$ from the multidose vial for a second flush. When the syringe was connected to the indwelling peripheral intravenous cannula the first time, the syringe might have become contaminated. Thus, using the same syringe to draw an additional $3 \mathrm{~mL}$ would subsequently contaminate the contents of the vial. Similar scenarios have been postulated for other nosocomial transmissions of blood-borne pathogens. ${ }^{6,13,24,25}$ In some outbreaks, investigators found that nurses would reuse syringes or cannulas for saline flushes for the same patient. ${ }^{24,26}$ This can occur with both needleless and traditional needle systems. ${ }^{16}$

This study has several limitations. First, 17 (41\%) of the 41 patients could not be tested for anti-HCV because 15 (37\%) of the patients had died before the investigation started. However, no history of HCV infection was documented in the medical records of these patients, and the death certificates did not mention liver disease. Second, we lacked sequencing data to determine how closely the virus genomes of patients $\mathrm{A}$ and $\mathrm{C}$ were related to the other samples. Third, the investigation started too late after the event for nurses to be able to remember any breaches in standard procedures. In addition, nurses might have been hesitant to admit such behaviors because they were aware that lawsuits were pending against the hospital. Fourth, we cannot exclude the possibility of intentional violation of standard procedures, such as described in a hepatitis $\mathrm{C}$ outbreak in Spain that involved drug addiction. ${ }^{27}$ However, the only occasion that any of the five patients with $\mathrm{HCV}$ infection received drugs with the potential for abuse or addiction was on November 14 when patient A received lorazepam.

Previous reports of nosocomial HCV transmission have suggested multidose saline solution vials as a source for transmission, but epidemiologic associations were not established.,6,10,11 Saline flushes and other intravenous multidose medications have also been reported to transmit blood-borne pathogens such as malaria, human immunodeficiency virus, or bacteria. ${ }^{1,13-16,24-26,28-35}$ For at least four reports of nosocomial transmission of blood-borne pathogens, investigators were able to epidemiologically link the transmission to saline flushes of indwelling peripheral intravenous cannulas. However, none of these reports included HCV. ${ }^{12,13,15,25}$

According to an Institute of Medicine report, medical errors occur at a high rate, and systems need to be designed to make it difficult for staff to make errors. ${ }^{36}$ Ideally, adherence to standard procedures would prevent contamination of a multidose vial or its contents. However, handling errors occur even among trained staff with adequate procedures in place, particularly during busy periods. ${ }^{3}$ Two changes could reduce, although not completely eliminate, the probability of contaminated saline flushes $^{24,37,38}$ : (1) multidose vials could be replaced by singledose vials or (2) single-use syringes prefilled with saline solution would reduce the need for vials entirely. Such products are available, and some hospitals have their pharmacy departments fill the syringes and deliver them in sterile packages to the units. ${ }^{37}$ As a result of this investigation, the affected hospital has replaced multidose saline vials with single-dose vials. A cost-benefit analysis for such interventions is needed, but the additional cost of singleuse saline vials or prefilled syringes is likely to be small.

\section{REFERENCES}

1. Sanchez-Tapias JM. Nosocomial transmission of hepatitis C virus. $J$ Hepatol 1999;31(suppl 1):107-112.

2. Bronowicki JP, Venard V, Botte C, et al. Patient-to-patient transmission of hepatitis C virus during colonoscopy. N Engl J Med 1997;337:237-240.

3. Schvarcz R, Johansson B, Nystrom B, Sonnerborg A. Nosocomial transmission of hepatitis C virus. Infection 1997;25:74-77.

4. Chant K, Kociuba K, Munro R, et al. Investigation of possible patient-topatient transmission of hepatitis C in a hospital. New South Wales Public Health Bulletin 1994;5:47-51.

5. Cody SH, Nainan OV, Garfein RS, et al. Hepatitis C virus transmission from an anesthesiologist to a patient. Arch Intern Med 2002;162:345-350.

6. Widell A, Christensson B, Wiebe T, Hansson HB, Allander T, Persson MA. Epidemiologic and molecular investigation of outbreaks of hepatitis C virus infection on a pediatric oncology service. Ann Intern Med 1999;130:130-134.

7. Grethe S, Gemsa F, Monazahian M, Bohme I, Uy A, Thomssen R. Molecular epidemiology of an outbreak of $\mathrm{HCV}$ in a hemodialysis unit: direct sequencing of HCV-HVR1 as an appropriate tool for phylogenetic analysis. J Med Virol 2000;60:152-158.

8. Allander T, Medin C, Jacobson SH, Grillner L, Persson MA. Hepatitis C transmission in a hemodialysis unit: molecular evidence for spread of virus among patients not sharing equipment. J Med Virol 1994;43:415-419.

9. Esteban JI, Gomez J, Martell M, et al. Transmission of hepatitis C virus by a cardiac surgeon. $N$ Engl J Med 1996;334:555-560.

10. Izopet J, Pasquier C, Sandres K, Puel J, Rostaing L. Molecular evidence for nosocomial transmission of hepatitis $\mathrm{C}$ virus in a French hemodialysis unit. J Med Virol 1999;58:139-144.

11. Allander T, Gruber A, Naghavi M, et al. Frequent patient-to-patient transmission of hepatitis C virus in a haematology ward. Lancet 1995;345:603607.

12. Abulrahi HA, Bohlega EA, Fontaine RE, al-Seghayer SM, al-Ruwais AA Plasmodium falciparum malaria transmitted in hospital through heparin locks. Lancet 1997;349:23-25.

13. Boswell T. Internal Report on an Outbreak of Malaria. Nottingham City Hospital NHS Trust; 2000.

14. Harbarth S, Sudre P, Dharan S, Cadenas M, Pittet D. Outbreak of Enterobacter cloacae related to understaffing, overcrowding, and poor hygiene practices. Infect Control Hosp Epidemiol 1999;20:598-603.

15. van Laer F, Raes D, Vandamme P, et al. An outbreak of Burkholderia cepacia with septicemia on a cardiology ward. Infect Control Hosp Epidemiol 1998;19:112-113.

16. Chodoff A, Pettis AM, Schoonmaker D, Shelly MA. Polymicrobial gramnegative bacteremia associated with saline solution flush used with a needleless intravenous system. Am I Infect Control 1995;23:357-363.

17. Centers for Disease Control and Prevention. Recommendations for prevention and control of hepatitis C virus (HCV) infection and HCV-related chronic disease. MMWR 1998;47(RR-19):1-39.

18. Nainan OV, Cromeans TL, Margolis HS. Sequence-specific, singleprimer amplification and detection of PCR products for identification of hepatitis viruses. J Virol Methods 1996;61:127-134.

19. Alter MJ, Kruszon-Moran D, Nainan OV, et al. The prevalence of hepatitis C virus infection in the United States, 1988 through 1994. N Engl J Med 1999;341:556-562.

20. Simmonds P, Holmes EC, Cha TA, et al. Classification of hepatitis C virus into six major genotypes and a series of subtypes by phylogenetic analysis of the NS-5 region. J Gen Virol 1993;74:2391-2399.

21. Enomoto N, Takada A, Nakao T, Date T. There are two major types of hepatitis C virus in Japan. Biochem Biophys Res Commun 1990;170:10211025.

22. Devereux J, Haeberli P, Smithies O. A comprehensive set of sequence analysis programs for the VAX. Nucleic Acids Res 1984;12:387-395.

23. Farci P, Shimoda A, Coiana A, et al. The outcome of acute hepatitis C predicted by evolution of the viral quasispecies. Science 2000;288:339-344.

24. Katzenstein TL, Jorgensen LB, Permin H, et al. Nosocomial HIV-transmission in an outpatient clinic detected by epidemiological and phylogenetic analyses. AIDS 1999;13:1737-1744.

25. Oren I, Hershow RC, Ben-Porath E, et al. A common-source outbreak of 
fulminant hepatitis B in a hospital. Ann Intern Med 1989;110:691-698.

26. Kantor RJ, Carson LA, Graham DR. Outbreak of pyrogenic reactions at a dialysis center: association with infusion of heparinized saline solution. Am J Med 1983;74:449-456.

27. Bosch X. Newspaper apportions blamed in Spanish hepatitis C scandal. Lancet 2000;355:818.

28. Hlady WG, Hopkins RS, Ogilby TE, Allen ST. Patient-to-patient transmission of hepatitis B in a dermatology practice. Am J Public Health 1993;83:1689-1693.

29. Longfield R, Longfield J, Smith LP, Hyams KC, Strohmer ME. Multidose medication vial sterility: an in-use study and a review of the literature. Infect Control 1984:5:165-169.

30. Welbel SF, McNeil MM, Kuykendall RJ, et al. Candida parapsilosis bloodstream infections in neonatal intensive care unit patients: epidemiologic and laboratory confirmation of a common source outbreak. Pediatr Infect Dis J 1996;15:998-1002.

31. Hutin YJ, Goldstein ST, Varma JK, et al. An outbreak of hospital-acquired hepatitis B virus infection among patients receiving chronic hemodialysis. Infect Control Hosp Epidemiol 1999;20:731-735.

32. Gremillion DH, Mursch SB, Lerner CJ. Injection site abscesses caused by Mycobacterium chelonei. Infect Control 1983;4:25-28.

33. Lettau LA. Nosocomial transmission and infection control aspects of parasitic and ectoparasitic diseases: II. Blood and tissue parasites. Infect Control Hosp Epidemiol 1991;12:111-121.

34. Navarro P, Betancurt A, Paublini $\mathrm{H}$, et al. Malaria causada por Plasmodium falciparum como infeccion nosocomial [Plasmodium falciparum malaria as a nosocomial infection]. Boletin de la Oficina Sanitaria Panamericana 1987;102:476-482

35. Alter MJ, Ahtone J, Maynard JE. Hepatitis B virus transmission associated with a multiple-dose vial in a hemodialysis unit. Ann Intern Med 1983;99:330-333.

36. Kohn LT, Corrigan JM, Donaldson MS, eds. To Err Is Human: Building a Safer Health System. Washington, DC: National Academy Press; 1999.

37. Rutala WA, Stiegel MM, Sarubbi FAJ. A potential infection hazard associated with the use of disposable saline vials. Infect Control 1984;5: 170-172.

38. McNeil MM, Solomon SL, Anderson RL, et al. Nosocomial Pseudomonas pickettii colonization associated with a contaminated respiratory therapy solution in a special care nursery. J Clin Microbiol 1985;22:903-907. 